\title{
Long-term causes of populism
}

\section{Gian Italo Bischi ${ }^{1} \cdot$ Federico Favaretto $^{2} \cdot$ Edgar J. Sanchez Carrera $^{1,3}$ (D)}

Received: 5 April 2020 / Accepted: 3 September 2020 / Published online: 14 September 2020

(C) The Author(s) 2020

\begin{abstract}
Why is populism emerging now in Europe? Why is it present in USA and Latin America? What model of political choice may explain these facts? Our paper addresses these questions by building an evolutionary game with two groups of players that decide whether to support a populist party by weighting demand for redistribution and demand for tough policy against immigration. Fundamentally, it is assumed that agents care about immigration the more they fear it and the higher number of other people care about it. Overall, positive shifts in the fear of immigration and increases in inequality drive citizens to converge toward supporting populists. The stability of the equilibria depends on the crucial parameters of the model, namely: fear of immigrants, the effect that the population type (the number of citizens supporting populism) have on individual preferences, economic inequality. Different equilibria represent different cases of populism: South-American left-wing populism and European right-wing populism. We propose that an economic society with a low inequality of wealth and with a low fear of immigrants is needed to avoid populism.
\end{abstract}

Keywords Behavioral economics · Economic and political behavior · Political party $\cdot$ Populism $\cdot$ Population games $\cdot$ Wealth inequality

JEL Classification C72 • C73 · D31 · D72 · E60 • H30

$凶 \quad$ Edgar J. Sanchez Carrera

edgar.sanchezcarrera@uniurb.it

Gian Italo Bischi

gian.bischi@uniurb.it

Federico Favaretto

favaretto@bc.edu

1 Department of Economics, Society, Politics, The University of Urbino Carlo Bo, Urbino, Italy

2 Economics Department, Morrissey College of Arts and Sciences, Boston College, Boston, USA

3 Research Fellow at CIMA UAdeC, Saltillo, Mexico 


\section{Introduction}

Populism consists in political movements that share a demand for short-term protection, such as from immigrants and economic hardship, and it is characterized by three main properties (Guiso et al. 2017): (i) the claim that it protects the people from the elite, (ii) the focus on demand-driven policymaking, and (iii) the disregard for future consequences of their policies. Lately, populism has fostered new enthusiasm and diverse research contributions, spurring from the emergence of parties and political movements labeled both as left-wing (South American populism described by Dornbusch and Edwards 1991; Acemoglu et al. 2013) and right-wing (mostly European and in USA).

In current times, populism is sweeping Europe's political equilibria. A report published by the Guardian in November 2018, (by a group of leading political scientists) found that one in four European voting citizens will be casting their vote for a populist. In addition, we know that there were nine European countries where populists participated in government, for a total of 170 million people in 2018: In 1998, the countries were 2 for a total of 12.5 million. According to this report, the surge in populism had an impact even where these parties did not govern: countries such as the UK, Sweden, Denmark, and Germany saw a strong shift to the right on immigration due to extreme right populist groups.

Populism seems to be associated with economic and financial crisis. Indeed if we categorize it as a close substitute to extreme parties on the right and the left, Funke et al. (2016) show that the vote for such parties spiked in elections held after systemic financial crises (in advanced economies between 1870 and 2014): support for extremist parties increased dramatically and especially for far-right parties $(+30 \%)$. Similar evidence for the period post-Great Depression is shown by De Bromhead et al. (2013) who find an increase in the share of votes for right-wing anti-system parties in elections in the 1920s and 1930s, thus confirming a link between political extremism and economic hard times.

This paper takes a different stand: Why is right-wing and left-wing populism emerging now? How do stable democracies with mild levels of economic and social problems suddenly see an important spike of preferences for populist parties? We believe that the answers rely on two long-term processes: an increase in the salience of immigration and an increase in income and wealth inequality. We take these two facts as given to build an evolutionary game, in order to understand under what conditions populism will be sustained (or not) in the long-run.

The first fact upon which our model is based, is that the salience of immigration almost doubled in Europe between 2010 and 2018 (Eurobarometer, see Fig. 1). This was also confirmed by Dennison and Geddes (2018), who noted that the most important issues for Europeans were immigration and unemployment in several countries. Rightwing populist parties reject immigration for a number of reasons including cultural and religious considerations. The key economic arguments against immigration claim that immigrants: (i) compete with natives in the labor market, take away their jobs and depress wages; and (ii) benefit from the welfare state and contribute little in the form of taxes. Populist parties also tend to reject the notion that migrants are refugees who leave their countries because of war and political prosecution. On the other hand, they 


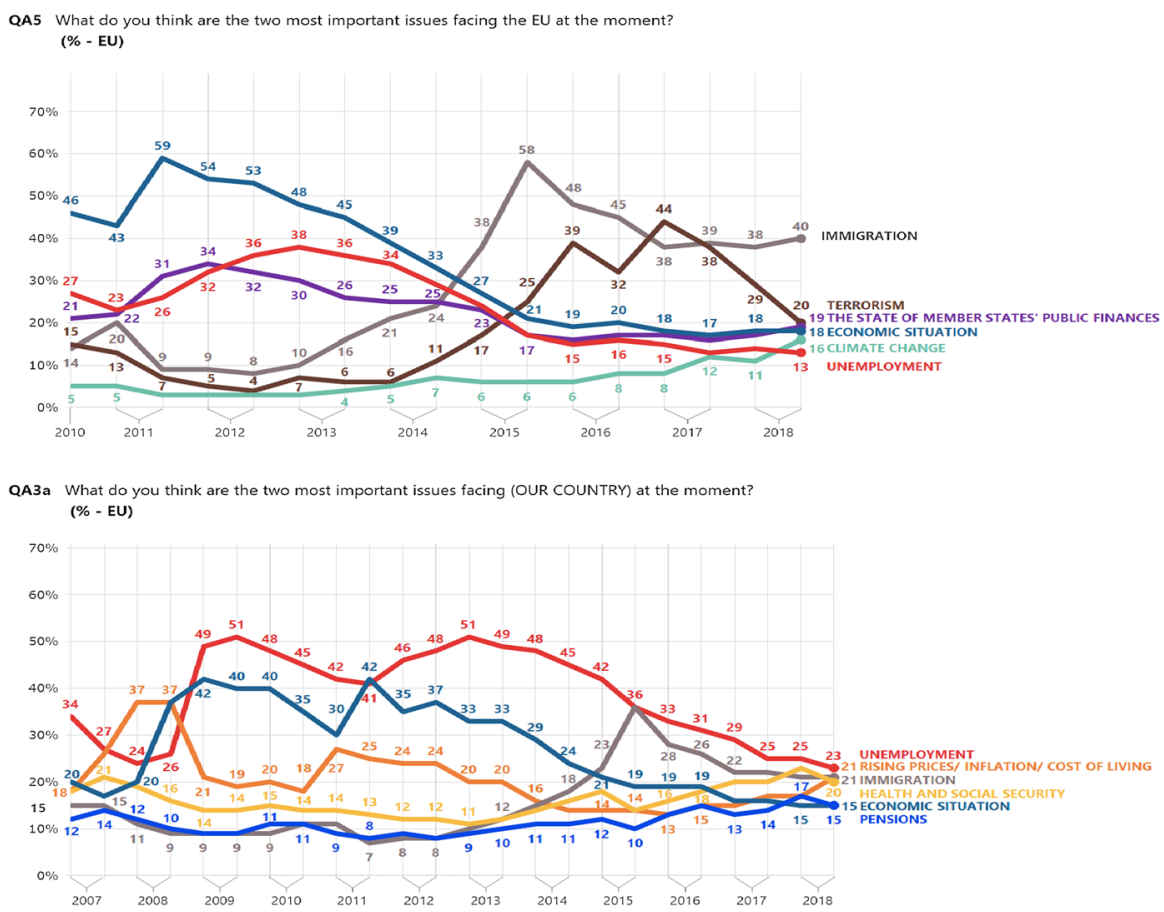

Fig. 1 Public opinion in the European Union. Source: Standard Eurobarometer 20. For data series and technical details, see: https://moien.lu/wp-content/uploads/2018/12/Eurobarometer-Nov_2018.pdf

claim that migrants are motivated by economic incentives and that many immigrants have entered the country illegally. This gives rise to calls for policy measures to reduce immigration. As a result, these parties propose radical changes to immigration policies. How radical these proposals are, differs considerably across populist parties (see EEAG 2017).

A second important fact is that economic inequality has increased substantially since 1980. The World Economic Forum (WEF) gathered data from the World Bank, the Organisation for Economic Co-operation and Development and other sources, along with other indicators to create the Inclusive Development Index 2018, a snapshot of the gap between rich and poor. According to the WEF index, economic inequality has risen or remained stagnant in 20 of the 29 advanced economies while poverty increased in 17. Moreover, the report states, both in advanced and emerging economies wealth is significantly more unequally distributed than income, and the problem of economic inequality has improved little in recent years. ${ }^{1}$ In this vein Han (2016) states that the average Gini coefficient of market (pre-tax, pre-transfer) income inequality in Western European countries increased by over $20 \%$ between 1980 and 2010 (the Standardized World Income Inequality Database, SWIID), and the average Gini coefficient of net (post-tax, post-transfer) income inequality increased by approximately $15 \%$ over the same period. In the past four decades, the poorest $80 \%$ Europeans' average incomes

\footnotetext{
1 See: http://www3.weforum.org/docs/WEF_Forum_IncGrwth_2018.pdf.
} 


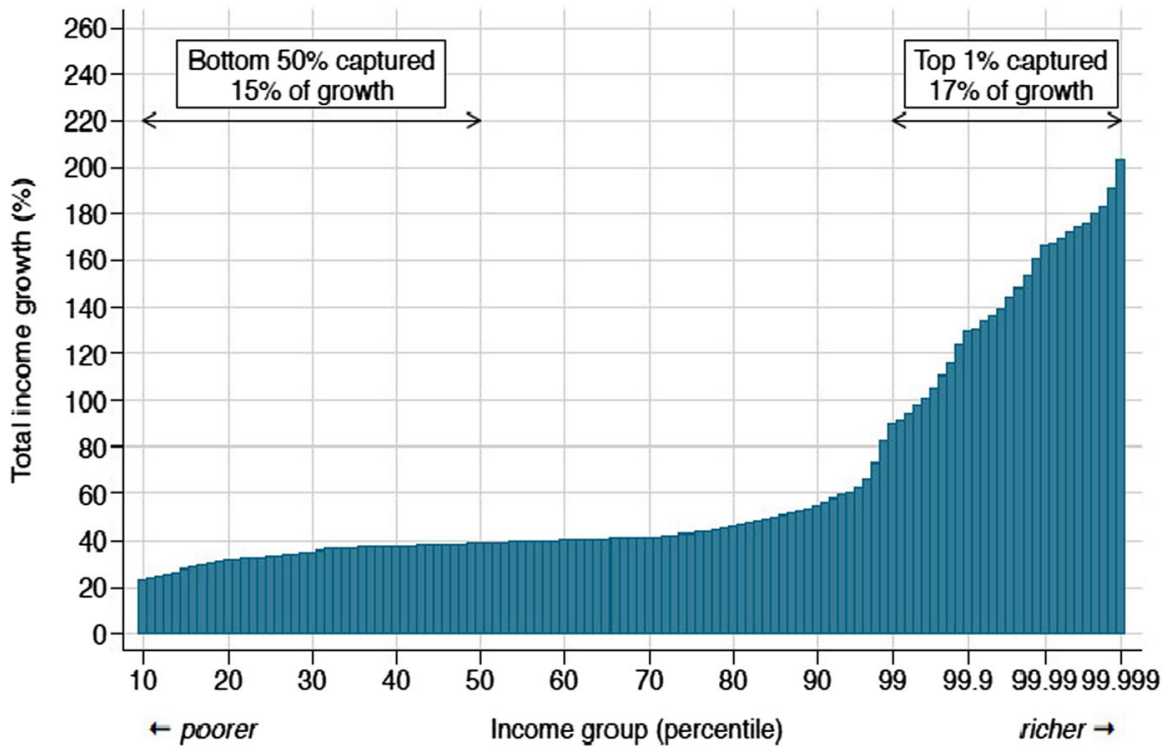

Fig. 2 Income inequality and growth in Europe: Growth incidence curve, 1980-2017. Source: Blanchet et al. (2019). For data series and technical details, see: www.wid.world/europe2019 and https://voxeu.org/ article/forty-years-inequality-europe

grew from about 20 to $50 \%$ (Fig. 2). As soon as one looks at richer income groups, however, growth rates are markedly higher, exceeding $100 \%$ for the top $1 \%$ and culminating at $200 \%$ for the top $0.001 \%$ of European citizens. Between 1980 and 2017, the top $1 \%$ alone captured $17 \%$ of European-wide growth, compared to $15 \%$ for the bottom $50 \% .^{2}$

Based on the above economic policy issues, this paper builds a political economy evolutionary game that defines a model of political choice based on demand for policies against immigration and economic inequality (populist policies looking for simplistic solutions to complex problems). We study what is called demand for populism, instead of the supply (Guiso et al. 2017; Rodrik 2018), taking for granted that there will be some suppliers of this political demand. We assume that populist parties are perceived by citizens as substantially more aggressive in pursuing these policies: populist leaders are not fully aware of institutional, law, administrative limitations and their rhetoric is grounded on changing overnight policy outcomes. For our framework, the essential part is that citizens believe populists to be more aggressive in pursuing these policies compared to mainstream center-right or center-left parties.

The advantage of immigration policy is that it relies on identity politics: strong words, fierce verbal opposition to immigration, a connection to violent right-wing groups, and a reference to traditional and religious values may all be part of it. Moreover, populists usually propose simple and catchy solutions to complex problems and this probably convinces relatively ignorant citizens that action has been taken. Notice

\footnotetext{
2 Between 1980 and 2017, the per adult real pre-tax income growth rate of the top $0.001 \%$ was $200 \%$, five times more than the growth rate of the bottom $80 \%$ of the population (about $40 \%$ ).
} 
that citizens vote on perceptions of policies: despite international laws on immigration and refugees, we assume that common citizens tend to prefer the party that promises to "flex more the muscles" against this potential threat from a cultural and identity standpoint.

We assume that citizens cannot distinguish a growth perspective between a populist government and a mainstream party one. A minority of citizens may have ideas about it, but by a great majority it is highly improbable that common citizens will penalize a populist party for fear of low economic growth.

In actual populists agenda, there is a strong tie with demand policies such as higher government spending using debt emission. Since we want to analyze long-term evolutionary equilibria, our approach does not focus on it because these policies are implemented only for a short period of time (few years) before taxes need to be increased. Moreover, these policies can last even less for highly indebted countries such as Italy, Greece and Portugal. By contrast, we consider a longer time frame that allows us to assume a Ricardian taxation framework: we assume that expansionary policies funded by debt will eventually be repaid by higher taxes or higher interests on government bonds due to default risk.

These assumptions allow us to concentrate on one key economic aspect of the vote for populists: the demand for less economic inequality. There is some evidence that high economic inequality is associated with higher support for extremist parties. For instance, Dorn et al. (2018) examine German counties and find that the poorer ones and the ones where within-county inequality was higher, had a higher share of votes for extremist parties.

We consider an evolutionary game with two groups of players and two strategies to study the economic and psychological consequences of supporting populism. How do the economic consequences for voting populists work? In our model, citizens are labeled as Rich and Poor at any time $t$ because of their pre-existing wealth. The division of citizens between Rich and Poor helps us to focus on distributional issues linked to voting. Hence, the Rich are assumed to work, while the Poor receive subsidies funded by distortionary taxation. This setup simplifies the economic inequality framework to a degree that the same group owns higher wealth and income. Hence, this allows us to focus on the effect of the redistribution policy by considering higher tax rate for the Rich. $^{3}$

Citizens evaluate whether to support populists based on two dimensions: whether the redistribution policy goes in their favor and by what amount and whether they have a non-economic benefit from supporting them. This benefit may be broadly conceived but we define it as the salience of immigration. How does the psychological benefit for voting populists work? We model a behavioral mechanism assuming that the elite (Rich) and the Poor may have different constant fears of immigrants due to, for example, self-protection against prospective offenders, higher proximity to housing competition, labor market competition or by higher neighborhood presence (Antoci

\footnotetext{
$3 \mathrm{We}$ are assuming that the alternative to populist is a classical party, either center-left or center-right, that is associated with moderate fiscal policies and moderate immigration policies. The political side of the populist party does not matter: according to Golder (2016) 'the precise content of the populist message is context-dependent' being against the established power-structures, and Guiso et al. (2017) states that the left or right orientation of a populist party depends on the political opportunity space.
} 
et al. 2017). At the top of the constant part, the fear of immigrants increases if other citizens become supporters of populism and decreases if otherwise. This assumption is based on a typical feature of politics: the more a party has support, the more citizens perceive that it will achieve its political goals. We allow for different marginal effects of citizens' support due to the fact that it is highly probable that the elite will value more the opinions and political choice of a fellow member than a Poor one. The idea that people refer to a group for psychological benefit comes from Passarelli and Tabellini (2017) and Favaretto and Masciandaro (2020). As opposed to other contributions, we assume that only non-economic issues are part of the psychological benefit of supporting populists.

We focus on the dichotomy classical versus populist parties, simplifying the political spectrum and reducing it to two parties to study which of the two should prevail in a long-term perspective. Our approach is compatible with all types of non-mainstream parties, namely populist, extremists, anti-system: this allows us to be as general as possible in capturing the two dimensions of voting. The only assumption that we care to underline is that as long as there are strong demands for these two types of policies, one or more populist parties will emerge to represent it. In our framework, we are able to consider these populists all together, as an expression of the same political demands. Hence, this paper makes several contributions. First, it provides a rational choice analysis of populism as populism is commonly understood. Second, it shows the long-term causes and hence the stability or instability of a populist system. Third, it addresses two questions: (i) what are the economic roots of populism? and (ii) what are the factors that affect the emergence of right- versus left-wing populism? Therefore our contribution is original in two ways. Firstly, we tackle the demand for populism by a game-theoretic approach (closely related to a political choice and/or behavioral economic model). Secondly, we use the evolutionary game theory approach that allows us to see how changes in the share of citizens that support populists affect the equilibria.

The structure of our paper is as follows. Section 2 offers a literature review highlighting what is our main contribution with respect to what already exists in the literature. Section 3 sets up the model, while Sect. 3.1 develops the replicator dynamics and it offers the dynamic equilibria and stability properties. Section 4 analysis the stability of the evolutionary equilibria showing the different cases and consequences for supporting or not supporting populism. Section 5 provides a conclusion.

\section{Literature review}

We consider the evolutionary game theory approach basically because we claim that agents are not perfectly rational (having common knowledge, in the economic sense) when supporting or not supporting populism. ${ }^{4}$ Then, we present a model that focuses

\footnotetext{
4 Noncooperative game theory has become a standard tool in modelling conflict between rational agents, where the Nash equilibrium is the cornerstone in predicting the outcome of the game. In a Nash equilibrium, each player's strategy maximizes her payoff, given the strategies played by the other players. No player, therefore, has an incentive to deviate from the Nash outcome, since it is the best situation for each individual player. But the constant in conventional game theory, including equilibrium refinements and the equilibrium
} 
on two deep and long-term causes of populism: economic inequality and salience of immigration. In this context, we are able to make a prediction on the persistence of populism in Europe. So our framework allows us to characterize also other forms of populism, such as the left-wing South-American one.

Recall that evolutionary games were first introduced in biology (Maynard Smith 1972; Maynard Smith and Price 1973) considering: (i) a selection process that favors some varieties/preferences over others, and (ii) a process that creates this variety, called the mutation process. In evolutionary game theory, the varieties in question are strategies in a game. In nature, the basic selection mechanism is biological survival and reproduction, and the mutation process is basically genetic. In the market place, the basic selection mechanism is economic survival through imitation of the better, and the mutation process is experimentation, externalities and mistakes. In both cases, there is also an element of individual and social learning. Hence, the starting point for an evolutionary model is the belief that people are not always rational as instead of choosing the best reply they are assumed to imitate people getting higher payoffs. Rather than springing into life as the result of a perfectly rational reasoning process in which each player, armed with the common knowledge of perfect rationality, solves the game, evolutionary games strategies emerge from a trial-and-error learning process in which players find that some strategies perform better than others, after which they decide to adopt or simply imitate such strategies. The agents may do very little reasoning in the course of this learning process. Instead, they simply take action, sometimes with great contemplation and sometimes with no thought at all. Their behavior is driven by rules of thumb, social norms, conventions, analogies to similar situations, or by other possibly more complex systems for converting stimuli into actions. In adopting this approach, evolutionary game theory assumes that the behavior driving the process by which agents adjust their strategies may not be perfectly rational, even though sometimes it may lead to "rational" equilibrium behavior in the long-run (Sanchez Carrera 2019).

Hence, we claim that by using an evolutionary game-theoretical approach we may be able to build a political choice model that goes beyond the current studies on the causes and consequences of populism. Our theoretical model finds a first-pass confirmation from the presence of strong statistical association between immigrant settlement and vote shares for right-wing populist parties: see Dustmann et al. (2017) for further references. Georgiadou et al. (2018) find data that support our setup: they use a new regional database of national and European parliament elections on NUTS 2 level in 28 countries and test the main theories explaining the electoral support for the European far right, part of which are what we defined as populists. The far right is divided into extremist (ER), that display elective affinities with historical fascism and

selection literature, is the belief that players are rational, and that this rationality is common knowledge. The common knowledge of rationality is often informally regarded as a necessary condition for there to be any hope that equilibrium will appear. Roughly speaking, the problems upon which an equilibrium refinement is built are often introduced with an appeal to the possibility that players might make mistakes, or that one can only understand "complete rationality as a limiting case of incomplete rationality (Selten 1975, p. 35)." Thus, the resulting problems typically affect the rules of the game (as in Selten's trembling hand perfection), the preferences of the players and the beliefs of the players. This brings us to the question of what can be learned from evolutionary game theory in studying the evolution of populations and the individual behavior of its members. 
populist radical right (PRR), that "deny any lineage" with the fascist legacies. They find evidence in support of both economic insecurity and cultural backlash theses (deriving from Inglehart and Norris 2016). Using a Tobit approach the ER vote is associated mostly with economic insecurity and the PRR vote mostly with cultural backlash. Unemployment, immigration and income inequalities have significant and robust effects at the sub-regional level.

There is evidence from Austria that shows a correlation between support for radical right parties (RRPs) and immigration concerns. Aichholzer and Zandonella (2016) study the social-psychological and personality bases of support for RRPs using structural equation models. Based on a sample of Austrian supporters for a radical right party, the FPO, they find that the main correlation for the support comes from a perceived immigrant threat. There is evidence that large flows of low educated immigrants in Europe made native voters support nationalistic parties (Moriconi et al. 2018). They consider individual data on party voting in parliamentary and presidential elections in 12 countries between 2007 and 2016, creating a classification of "nationalistic attitudes" for parties within the electoral competition. Estimates show that the education level of immigrants is crucial in determingin whether large inflows of immigrants changed the voting patterns of natives compared to nationalism. Only the inflow of less educated immigrants is positively associated with the increase of votes toward nationalistic positions and it is stronger for non-tertiary educated voters and in response to non-European immigrants.

Han (2016) presents evidence in line with our setup: higher income inequality is associated with increases in votes for radical right-wing parties (a subset of our definition of populists), but only for the poor. Indeed the Rich people's vote for these parties is negatively associated with increase in inequality. More specifically, using a multilevel analysis method, Han (2016) tests different hypotheses for how income inequality affects voter support for radical right-wing parties (RRPs) in Western Europe (these parties are defined as nationalist, but not anti-system parties). Income inequality encourages poor people to vote for RRPs, while it discourages rich people from doing so. The evidence indicates that while income inequality increases support among the poor for RRPs in Western Europe, it decreases support among rich people for these parties.

On the demand for populism, there have been several contributions. Favaretto and Masciandaro (2020) consider one theoretical mechanism for explaining the emergence of populism rooted in three broad concepts: a massive economic shock that requires a public decision on policy, individuals that have different incentives to vote for a populist party based on their wealth group, a voting decision that is behavioral and depends on wrong sense of entitlements by each group. Populism in Europe is seen as a democratic riot: people express their anger by voting an alternative to a traditional party since they think they deserve more as a group. The assumption is that by voting for a populist party, individuals get psychological benefit by seeing that other group members did the same and voice their anger at the old politicians. Such public display of anger is key to voting a populist party, as it was rioting together in the streets in Passarelli and Tabellini (2017). Our approach is similar for the use of behavioral mechanisms for the emergence of populism, the difference being that we use a psychological benefit that is non-economic and related to the fear of immigration. 
Pastor and Veronesi (2018) build a heterogenous agent model with agents' utility modeled as inequality averse. In a setting where the US is compared to the Rest of the World and there are individual-level differences in risk aversion, economic growth increases inequality within both countries because less risk-averse agents consume a growing share of total output. In this model, globalization brings populism through effects of risk sharing. Indeed, agents with low risk aversion consume more overtime, widening the inequality until a point where it is beneficial for a majority to halt risk sharing and trade to limit within-country inequality by voting a populist candidate. This theory implies that the surfacing of populism is cyclical and it happens when economic growth is strong, since the loss of income due to autarky has less of an effect on the marginal utility of consumption during expansions. This analysis may fit well with the vote for Trump, but less so for European populists.

Algan et al. (2017) use regional-level data on voting in Europe after the Great Recession and find that economic insecurity is a major driver of populist voting. In particular, increases in unemployment are correlated with increases in votes for populist parties. Acemoglu et al. (2013) model left-wing populism with a signaling mechanism. Aggeborn and Persson (2017) build a model where support for right-wing politicians comes from poor people because they prefer to use the basic public services instead of a global public good (assumed to be offered by left-wing politicians). Di Tella and Rotemberg (2018) build a model where populism emerges as a demand for insurance against betrayal. They define populists as incompetent politicians: in a world where there is no way to control corruption, they assume that betrayal-averse agents may vote for them to limit the scenario of an elite betrayal.

In our model, we take as given a certain amount of economic inequality. One possible explanation for the increase in economic inequality comes from trade shocks. There is a vast literature on the effect of globalization on voting patterns, which focuses on voting patterns associated with decreased wages among unskilled workers by rising competition from low/middle income countries (Autor et al. 2016a, b; Colantone and Stanig 2018). This story fits with ours: economic shocks that create a larger divide between unskilled and skilled workers make their demand for redistribution higher, hence creating higher incentives for the Poor to vote for populists.

There is evidence that variables related to personal emotions are very important in order to understand votes for populist parties such as the Front Nationale of Marine Le Pen. Indeed Algan et al. (2018) analyze voting choices in France and they find that votes on the new diagonal opposing "open versus closed society" are predicted by individual and subjective variables. More specifically, low well-being predicts antisystem opinions (from the left or from the right) while low interpersonal trust (ITP) predicts right-wing populism. Moreover, our model builds on the intuition that perception of immigration is key to analyzing populism. Dustmann and Preston (2007) are interested in attitudes toward immigrants. They specify and estimate a multiple factor model that allows for a comparison of the relative magnitude of association of attitudes to immigration with three channels: labor market concerns, welfare concerns, and racial or cultural concerns. Welfare concerns play a more important role in determining attitudes to further immigration than labor market concerns and there is strong evidence that racial or cultural prejudice is an important component in attitudes toward ethnically different immigrants. Bad attitudes toward immigrants have a strong 
component that is purely given by their presence in the public space. Moreover, this effect is widely held by individuals with lower education. Indeed Card et al. (2012) compare attitudes toward immigrants in Europe using data for 21 countries from the 2002 European Social Survey (ESS) and consider a latent-factor model to account for the composition of local population. They find that immigrants are a threat to the compositional amenities that natives derive from their neighborhoods, schools, and workplaces. They find that compositional concerns are 2-5 times more important in explaining variation in individual attitudes toward immigration policy than concerns over wages and taxes. Moreover, most of the difference in opinion between moreand less-educated respondents is attributable to heightened compositional concerns among people with lower education.

We use a setup in which group decisions affect the psychological benefit of the individual for voting populists, which is based on the well-known notion of "social interactions" (Antoci and Sabatini 2018). In his seminal contribution (Schelling 1969, 1971), underlines how discriminatory individual choices lead to the segregation of groups of people of different kinds. Citizens get separated for different reasons, such as sex, age, income, language or nationality, color of the skin, and the like. More recently, evolutionary game theory has been applied to study such situations in which the choices between two alternatives are influenced by social interactions resulting in the existence and stability of equilibrium points, as well as the creation of more complex attractors (periodic or chaotic) related with overshooting effects (see Bischi et al. 2018).

Some evidence on the importance of groups in making political decisions comes from Mutz and Mondak (1997). They find that group-level economic perceptions have an impact on political evaluations. Using data from the 1984 South Bend Study on the presidential vote choice, they find that group-level economic perceptions matter in the choice of vote as independent forces from the nation-level and family-level ones. The unique form of group-comparison regards "fairness" among groups: if groups have been treated fairly, there is higher support for the president. Blacks, poor people and well-to-do have statistically significant effects among group-level economic perceptions.

Studies from social psychology prove how much individual behavior is affected by a group's affiliation. Indeed Gerber and Rogers (2009) explain that there is a growing literature on social norm perception and that people consider strongly what other people do in a given situation: beliefs about how other people act, called descriptive social norms, exert powerful influence across a range of behaviors. They explain that group membership influences individual political attitudes and behavior.

In addition, the Columbia school (e.g., Berelson et al. 1954) explains individual voting behavior as the product of group affiliations such as religion, ethnicity, and occupation and argue that group pressure leads to conformity. In addition, information about politics is heavily dependent on group behavior (Huckfeldt and Sprague 1995). Social-identity theory (Tajfel 1982) states that group members are motivated to conform with norms that provide them with an in-group identity. Overall, the evidence from social psychology and social-norm marketing confirms that group norms and group membership influence broad political behavior and individual voting behavior through social norms and information. In general conformity to these approaches, 
our model assumes that individuals are affected by decisions made by people of their own economic group as well as the other economic group.

\section{The evolutionary game}

Consider that citizens (i.e., players or economic agents) are either rich, $(R)$, or poor, $(P)$, with two different strategies regarding populism: supporting and not-supporting, i.e., $(S, N S)$. Assume that:

- Wealth of an individual of class $i=\{R, P\}$ is denoted by $W_{i}>0$. Labor income is denoted by $I>0$.

- Poor people do not work and receive transfers from proportional taxation from the rich. Transfers to Poor people is denoted by $T_{j}>0, \forall j=\{S, N S\}$.

- Citizens $R$ face a tax rate on global income and wealth, defined by $\bar{\tau} \in(0,1)$ or $\tau \in(0,1), \bar{\tau}>\tau$, which depends on whether a populist policy is ongoing or not. ${ }^{5}$ The purpose of such taxes, whether by populists and non-populists, is to guarantee a social welfare system.

- Being in favor of populism implies an expectation of some psychological benefits, denoted by $a_{i}(\cdot) \in \mathbb{R}, \forall i=\{R, P\}$, depending on exogenous salience of immigration policy.

Hence, a possible normal-form representation of this game is presented in the following payoff matrix,

\begin{tabular}{|c|c|c|}
\hline$R \backslash P$ & $\mathbf{N S}$ & $\mathbf{S}$ \\
\hline $\mathbf{N S}$ & $(1-\tau)\left(W_{R}+I\right), W_{P}+T_{N S}$ & $(1-\tau)\left(W_{R}+I\right), W_{P}+T_{N S}+a_{P}$ \\
\hline $\mathbf{S}$ & $(1-\bar{\tau})\left(W_{R}+I\right)+a_{R}, W_{P}+T_{S}$ & $(1-\bar{\tau})\left(W_{R}+I\right)+a_{R}, W_{P}+T_{S}+a_{P}$ \\
\hline
\end{tabular}

Notice that, if $a_{p}>0$ and $a_{R}>\left(W_{R}+I\right)(\bar{\tau}-\tau)$ then supporting populist' strategy is best for a player no matter what strategy the other player uses, i.e., such $S$-strategy is called a dominant strategy. The game may be expressed as a coordination-game with two pure Nash equilibria:

$(N S, N S)=((1,0) ;(1,0)) \quad$ if $\quad a_{i}<0, \quad$ and $\quad(S, S)=((0,1) ;(0,1)) \quad$ if $\quad a_{i}>0$,

There is a mixed strategy Nash equilibrium occurring when the psychological benefits from populism are equal to some reference value, i.e., $a_{R}^{*}=\left(W_{R}+I\right)(\bar{\tau}-\tau)$ and $a_{P}^{*}=0$, such that citizens are indifferent between $N S$ and $S$. So, if the psychological benefits of populism are equal to the after-tax wealth on the part of the rich and to a zero

\footnotetext{
5 In actual populists agenda, there is a strong tie with demand policies such as higher government spending using debt emission. Since we want to analyze long-run evolutionary equilibria, our approach does not focus on it because these policies are implemented only for a short period of time (few years) before taxes need to be increased. Moreover, these policies can last even less for highly indebted countries such as Italy, Greece and Portugal. Instead, we consider a longer time frame that allows us to assume a Ricardian taxation framework: we assume that expansionary policies funded by debt will eventually be repaid by higher taxes or higher interests on government bonds due to default risk.
} 
benefit on the part of the poor, then such citizens are indifferent between supporting or not supporting populism.

The next section analyzes this game as an evolutionary process. Recall that the term evolutionary means that the more successful types $\{S, N S\}$ tend to proliferate while less successful tend to disappear, an assumption that applies equally well to learning by imitation and cultural evolution as well as to literal population replacement by natural selection. The model applies as long as people tend to gravitate toward a behavior that does better than alternative ones.

One more observation before moving on to the dynamic part of the game, i.e., the transfers to the poor in both supporting and non-supporting cases is absent in the system dynamics. The intuition behind this that the only fiscal policy is the redistributive one, hence in the above described one-shot game, the net taxation is equal to the difference in transfer to the Poor.

\subsection{Replicator dynamics}

A simple setting to study the time evolution of the adaptive process described above, is one in which agents' strategies can be observed at any time and single agents have no impact on what they observe. Hereafter, total populations of Rich $(R)$ and Poor $(P)$ are normalized, i.e., the populations of Rich is $\left(x_{N S}+x_{S}\right)=1$ and the population of Poor is $\left(y_{N S}+y_{S}\right)=1$.

That is, $x_{j}$ and $y_{j}$ denote the fractions of Rich and Poor individuals choosing the $j$-strategy $(j \in\{N S, S\})$.

We define psychological benefits of supporting populists as:

$$
\begin{aligned}
& a_{R}=\alpha-\beta_{1} x_{N S}-\beta_{2} y_{N S} \\
& a_{P}=\gamma-\sigma_{1} y_{N S}-\sigma_{2} x_{N S}
\end{aligned}
$$

where $\alpha \geq 0$ and $\gamma \geq 0$ are the exogenous components of the psychological benefit: if they are higher, then more individuals in the corresponding group, $R$ or $P$, fear immigrants; $\beta_{1}>0, \beta_{2} \geq 0, \sigma_{1}>0$ and $\sigma_{2} \geq 0$ measure how the groups are affected by the share of citizens non-supporting populism $\left(x_{N S}, y_{N S}\right)$. We assume that the psychological benefit is growing in the amount of group peers that are supporting populist, hence the formulation for which every additional non-supporting individual is diminishing the psychological benefits: $\frac{\partial a_{R}}{\partial x_{N S}}<0, \frac{\partial a_{R}}{\partial y_{N S}} \leq 0$ and $\frac{\partial a_{p}}{\partial y_{N S}}<0 \frac{\partial a_{p}}{\partial x_{N S}} \leq 0$, i.e., these are decreasing or non-increasing functions with respect to the corresponding share of non-supporting citizens on populism (notice that it may happen that the psychological benefits should not be affected by a greater number of non-populist individuals belonging to the other group).

Hence, from the above considerations we may establish that the expected payoffs of Poor and Rich citizens are:

$$
\begin{aligned}
E_{N S}^{P} & =x_{N S}\left(T_{N S}-T_{S}\right)+W_{P}+T_{S} \\
E_{S}^{P} & =x_{N S}\left(T_{N S}-T_{S}\right)+W_{P}+T_{S}+\gamma-\sigma_{1} y_{N S}-\sigma_{2} x_{N S}
\end{aligned}
$$




$$
\begin{aligned}
E_{N S}^{R} & =(1-\tau) \bar{W} \\
E_{S}^{R} & =(1-\bar{\tau}) \bar{W}+\alpha-\beta_{1} x_{N S}-\beta_{2} y_{N S}
\end{aligned}
$$

where $\bar{W}=W_{R}+I$. The corresponding average payoffs are given by

$$
\begin{aligned}
\bar{E}^{P} & =y_{N S}\left(E_{N S}^{P}\right)+\left(1-y_{N S}\right)\left(E_{S}^{P}\right) \\
\bar{E}^{R} & =x_{N S}\left(E_{N S}^{R}\right)+\left(1-x_{N S}\right)\left(E_{S}^{R}\right) .
\end{aligned}
$$

Let us consider replicator dynamics with 2 populations $\{R, P\}$ (see Taylor 1979; Weibull 1995,172 ) in order to explicitly model a selection process, specifying how population shares associated with different pure strategies in a game evolve over time. ${ }^{6}$ Given the above expected payoffs, where in order to simplify the notations we define $x=x_{N S}$ and $y=y_{N S}$ so that $x_{S}=1-x$ and $y_{S}=1-y$, we get the replicator dynamics represented by the following system of two differential equations,:

$$
\left\{\begin{array}{l}
\dot{x}=x\left[E_{N S}^{R}(\cdot)-\bar{E}^{R}\right]=x(1-x)\left[\bar{W}(\bar{\tau}-\tau)-\alpha+\beta_{1} x+\beta_{2} y\right] \\
\dot{y}=y\left[E_{N S}^{P}(\cdot)-\bar{E}^{P}\right]=y(1-y)\left[\sigma_{1} y+\sigma_{2} x-\gamma\right]
\end{array}\right.
$$

In other words, the proportion of agents using strategy $N S$ increases if its payoff is bigger than the average payoff of the population. System (7) is a nonlinear twodimensional dynamical system in continuous time. The first step to shed some light on its qualitative dynamic behavior is the study of the existence of equilibrium points: their localization (obtained by solving an algebraic system of degree 9) and their local stability properties. These results are summarized by the following propositions.

Proposition 1 (Existence of steady states) The dynamic model (7) has at most nine equilibrium points according to the following classification:

- Four corner equilibria:

$$
\begin{aligned}
& E_{o o}=(0,0)(\text { all citizens supporting populism); } \\
& E_{11}=(1,1)(\text { all citizens non-supporting populism); } \\
& E_{10}=(1,0)(\text { rich people non-supporting populism versus all poor supporting } \\
& \text { populism }) ; \\
& E_{01}=(0,1) \text { (all rich are supporting populism versus all poor non-supporting } \\
& \text { populism). }
\end{aligned}
$$

- Four boundary equilibria:

$E_{L}=\left(0, \frac{\gamma}{\sigma_{1}}\right)$, if $\frac{\gamma}{\sigma_{1}} \leq 1$ (all rich supporting populism and a fraction of poor population supporting it);

\footnotetext{
6 The mathematical formulation of the replicator dynamics is due to Taylor and Jonker (1978). They imagine a large population of agents who are randomly matched over time to play a finite symmetric two-player game, just as in the setting for evolutionary stability. Studying the replicator dynamics of a system is an increasingly utilized tool for understanding the evolution, for example, of institutions and social norms, providing many applications in economics (see Gintis 2009; Sanchez Carrera 2016).
} 
$E_{R}\left(1, \frac{\gamma-\sigma_{2}}{\sigma_{1}}\right)$, if $\sigma_{2} \leq \gamma \leq \sigma_{1}+\sigma_{2}$ (all rich non-supporting populism and $a$ fraction of poor population supporting it);

$E_{B}=\left(\frac{\alpha-\bar{W}(\bar{\tau}-\tau)}{\beta_{1}}, 0\right)$, if $0 \leq \alpha-\bar{W}(\bar{\tau}-\tau) \leq \beta_{1}$ (a fraction of rich citizens supporting populism and all poor citizens supporting it);

$E_{U}=\left(\frac{\alpha-\bar{W}(\bar{\tau}-\tau)-\beta_{2}}{\beta_{1}}, 1\right)$, if $\beta_{2} \leq \alpha-\bar{W}(\bar{\tau}-\tau) \leq \beta_{1}+\beta_{2}$ (a fraction of rich citizens supporting populism and no poor citizens supporting it).

- An interior equilibrium $E_{*}=\left(x^{*}, y^{*}\right)$ given by:

$$
\left(x^{*}=\frac{\gamma \beta_{2}+\sigma_{1}(\bar{W}(\bar{\tau}-\tau)-\alpha)}{\beta_{2} \sigma_{2}-\beta_{1} \sigma_{1}}, \quad y^{*}=\frac{\gamma \beta_{1}+\sigma_{2}(\bar{W}(\bar{\tau}-\tau)-\alpha)}{\beta_{1} \sigma_{1}-\beta_{2} \sigma_{2}}\right) \text {, }
$$

provided that: $\beta_{1} \sigma_{1} \neq \beta_{2} \sigma_{2}, 0<x^{*}<1$ and $0<y^{*}<1$ (a fraction of rich citizens as well as a fraction of poor citizens supporting populism).

Proposition 2 (Stability of steady states) Given the existence of such equilibrium points (Proposition 1), their local stability properties are as follows:

- The interior equilibrium $E_{*}$ is always unstable; it is a saddle point if $\beta_{1} \sigma_{1}<\beta_{2} \sigma_{2}$; it is a repelling node if $\beta_{1} \sigma_{1}>\beta_{2} \sigma_{2}$.

- For the corner and boundary equilibrium points, the following holds:

- E00is an attracting node if $\alpha>\bar{W}(\bar{\tau}-\tau)$ and a saddle point (with stable manifold along y axis and unstable manifold along $x$ axis) if $\alpha<\bar{W}(\bar{\tau}-\tau)$;

- $E_{11}$ is an attracting node if $\alpha<\beta_{1}+\beta_{2}+\bar{W}(\bar{\tau}-\tau)$ and $\gamma<\sigma_{1}+\sigma_{2}$, a repelling node if $\alpha>\beta_{1}+\beta_{2}+\bar{W}(\bar{\tau}-\tau)$ and $\gamma>\sigma_{1}+\sigma_{2}$, a saddle point (with stable manifold along the vertical edge and unstable manifold along the horizontal edge) if $\alpha>\beta_{1}+\beta_{2}+\bar{W}(\bar{\tau}-\tau)$ and $\gamma<\sigma_{1}+\sigma_{2}$, a saddle point (with unstable manifold along the vertical and stable manifold along horizontal edge) if $\alpha<\beta_{1}+\beta_{2}+\bar{W}(\bar{\tau}-\tau)$ and $\gamma>\sigma_{1}+\sigma_{2}$;

- $E_{01}$ is an attracting node if $\alpha>\beta_{2}+\bar{W}(\bar{\tau}-\tau)$ and $\gamma<\sigma_{1}$, a repelling node if $\alpha<\beta_{2}+\bar{W}(\bar{\tau}-\tau)$ and $\gamma>\sigma_{1}$, a saddle point (with stable manifold along the vertical edge and unstable manifold along horizontal edge) if $\alpha<$ $\beta_{2}+\bar{W}(\bar{\tau}-\tau)$ and $\gamma<\sigma_{1}$, a saddle point (with unstable manifold along the vertical hedge and stable manifold along horizontal edge) if $\alpha>\beta_{2}+\bar{W}(\bar{\tau}-\tau)$ and $\gamma>\sigma_{1}$;

- $E_{10}$ is an attracting node if $\alpha<\beta_{1}+\bar{W}(\bar{\tau}-\tau)$ and $\gamma>\sigma_{2}$, a repelling node if $\alpha>\beta_{1}+\bar{W}(\bar{\tau}-\tau)$ and $\gamma<\sigma_{2}$, a saddle point (with stable manifold along the vertical edge and unstable manifold along horizontal edge) if if $\alpha<$ $\beta_{1}+\bar{W}(\bar{\tau}-\tau)$ and $\gamma<\sigma_{2}$, a saddle point (with unstable manifold along the vertical edge and stable manifold along horizontal edge) if $\alpha>\beta_{1}+\bar{W}(\bar{\tau}-\tau)$ and $\gamma>\sigma_{1}$;

- $E_{L}$ is never stable when it exists: a saddle point with unstable manifold along the vertical edge, and stable manifold transverse to it, if $\alpha>\frac{\gamma \beta_{2}}{\sigma_{1}}+\bar{W}(\bar{\tau}-\tau)$, a repelling node if $\alpha<\frac{\gamma \beta_{2}}{\sigma_{1}}+\bar{W}(\bar{\tau}-\tau)$; 
$-E_{R}$ is an attracting node if $\alpha<\beta_{1}+\frac{\left(\gamma-\sigma_{2}\right) \beta_{2}}{\sigma_{1}}+\bar{W}(\bar{\tau}-\tau)$ and $\gamma>2 \sigma_{2}$, a repelling node if $\alpha>\beta_{1}+\frac{\left(\gamma-\sigma_{2}\right) \beta_{2}}{\sigma_{1}}+\bar{W}(\bar{\tau}-\tau)$ and $\gamma<2 \sigma_{2}$, a saddle point (with stable manifold along the vertical edge and unstable manifold transverse to it) if $\alpha>\beta_{1}+\frac{\left(\gamma-\sigma_{2}\right) \beta_{2}}{\sigma_{1}}+\bar{W}(\bar{\tau}-\tau)$ and $\gamma>2 \sigma_{2}$, a saddle point (with unstable manifold along the vertical edge and stable manifold transverse to it) if $\alpha<\beta_{1}+\frac{\left(\gamma-\sigma_{2}\right) \beta_{2}}{\sigma_{1}}+\bar{W}(\bar{\tau}-\tau)$ and $\gamma<2 \sigma_{2}$;

- $E_{B}$ is never stable when it exists: a saddle point with stable manifold along the horizontal edge, and unstable manifold transverse to it, if $\gamma>$ $\frac{\alpha_{2}}{\beta_{1}}(\alpha-\bar{W}(\bar{\tau}-\tau))$, a repelling node otherwise;

- $E_{U}$ is never stable when it exists: a saddle point with stable manifold along the horizontal edge, and unstable manifold transverse to it, if $\gamma<\sigma_{1}+$ $\frac{\sigma_{2}}{\beta_{1}}\left(\alpha-\beta_{2}-\bar{W}(\bar{\tau}-\tau)\right)$, a repelling node otherwise;

From the above proposition we can state the following corollary on transcritical bifurcations (or stability exchange) for two distinct equilibria that overlap and swap (in our case one exits from the square) for a given set of parameters, exchanging stability in the direction in which they intersect. In our case this happens when a boundary equilibrium ends in the corner or when the interior equilibrium ends up on a boundary.

Corollary 1 Whenever two of the equilibrium points listed in the Proposition 1 merge and swap a transcritical bifurcation occurs at which one equilibrium exits the feasible unitary square and exchanges its stability with the other one.

For example, at $\sigma_{2}=\gamma$ we have $E_{R}=E_{10}$ and the if $\gamma$ decreases then $E_{R}$ exits the unit interval whereas $E_{10}$ becomes unstable along the vertical axis. Analogously, when $\alpha=\bar{W}(\bar{\tau}-\tau)$ we have $E_{B}=E_{00}$, and if $\alpha$ is decreased then $E_{B}$ exits the unit interval whereas $E_{00}$ becomes unstable along the horizontal invariant edge; when $\alpha=\bar{W}(\bar{\tau}-\tau)+\beta_{1}$ we have $E_{B}=E_{10}$, if $\gamma=\sigma_{1}$ then $E_{L}=E_{10}$, if $\alpha=\bar{W}(\bar{\tau}-\tau)+\beta_{2}$ then $E_{U}=E_{01}$, if $\alpha=\bar{W}(\bar{\tau}-\tau)+\beta_{1}+\beta_{2}$ then $E_{U}=E_{11}$, if $\alpha-\bar{W}(\bar{\tau}-\tau)=\frac{\beta_{1 \gamma}}{\sigma_{1}}$ then $E_{*}=E_{L}$, if $\alpha-\bar{W}(\bar{\tau}-\tau)=\frac{\beta_{1} \gamma}{\sigma_{2}}$ then $E_{*}=E_{B}$, etc.

Remark 1 When two attracting nodes co-exist at the corners or along the invariant edges, then the interior equilibrium $E_{*}$ lies along the boundary that separates the two basins of attraction. This means that the distance between $E_{*}$ and a stable equilibrium along the edges of the unit square gives a proxy of the robustness of the stability of the stable equilibrium. Robustness in the sense of amplitude of displacements from the equilibrium that are recovered by endogenous dynamics of the system, i.e., such that the spontaneous dynamics of the system will lead again to the equilibrium.

Next, let us move on to some economic interpretations of these results, and analyze some feasible political meanings of these equilibrium points. In other words, we are interested in the political and economic interpretations of the above mathematical results. 


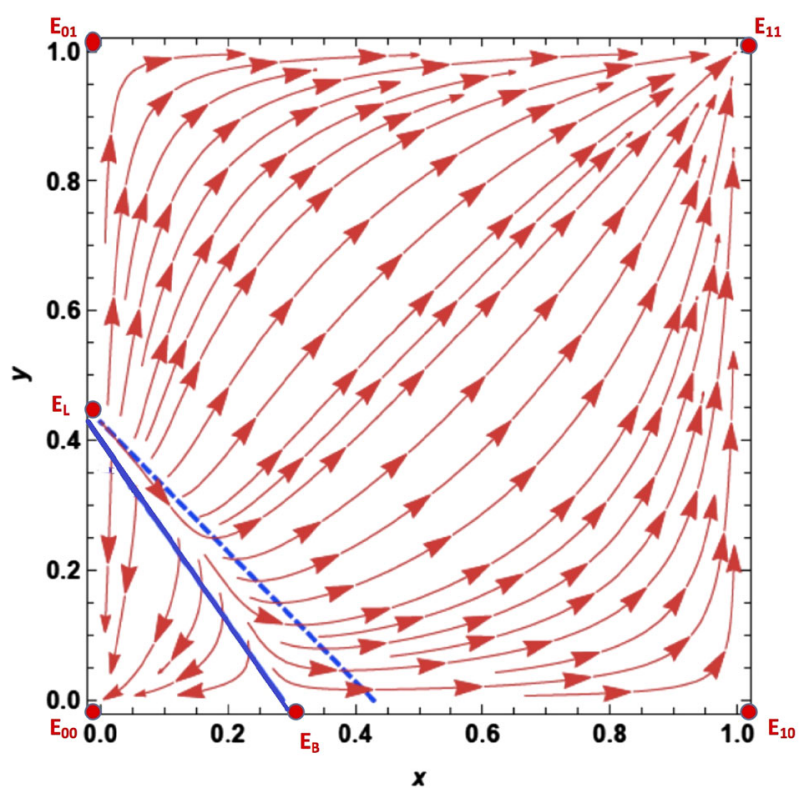

Fig. 3 Convergence toward not supporting populism, $E_{11} \ldots$ Source: Own elaboration using Wolfram Mathematica. Vector field of system (7). The parameters defined by $\sigma_{1}=0.7, \sigma_{2}=0.7, \beta_{1}=0.7$ and $\beta_{2}=0.5$ (they may range also between $(0.6,1)$ ), and $\alpha=0.3, \gamma=0.3$ (it holds also for values lower than 0.4$)$. The straight blue line is $(1-x) x(-0.2+0.7 x+0.5 y)=0$, and the dashed blue line is $(1-y) y(-0.3+0.7 x+0.7 y)=0$, i.e., the two nullclines (color figure online)

\section{Interpreting the results as varieties of populism}

Let us consider a first scenario characterized by low fear of immigrants and low economic inequality. The case in which the population does not support populism in the long run is represented by the equilibrium $E_{11}$. The intuition behind the stability condition for this equilibrium is that: i) the psychological benefits of supporting populism due to the fear of immigrants are low, ii) inequality is not high enough (in the following numerical simulations the condition for low inequality is represented by $\bar{W}=1$ ), and iii) the marginal effects, $\beta_{1}+\beta_{2}$ and $\sigma_{1}+\sigma_{2}$, on the psychological benefit of other not-supporting citizens is high. Hence, equilibrium $E_{11}$ is an attracting node if $\alpha-\bar{W}(\bar{\tau}-\tau)<\beta_{1}+\beta_{2}$ and $\gamma<\sigma_{1}+\sigma_{2}$. Then, both Rich and Poor agents converge toward not supporting populism (Fig. 3) given the redistribution policy. ${ }^{7}$ This may happen in a society where the Poor group has very conservative values that dampens their relative desire of redistribution and there are no bad feelings with regards to immigrants. The third condition above implies that the marginal impact of a citizen that shift to not supporting populists is big enough in eroding the constant part of the fear of immigrants. In other words, in this scenario the fear of immigrants spreads slowly.

\footnotetext{
7 We assume that the payment of taxes is around $40 \%$ when there is a populist economic policy $(\bar{\tau}=0.4)$ and that it is $30 \%$ when populist economic policies are not applied $(\tau=0.3)$.
} 


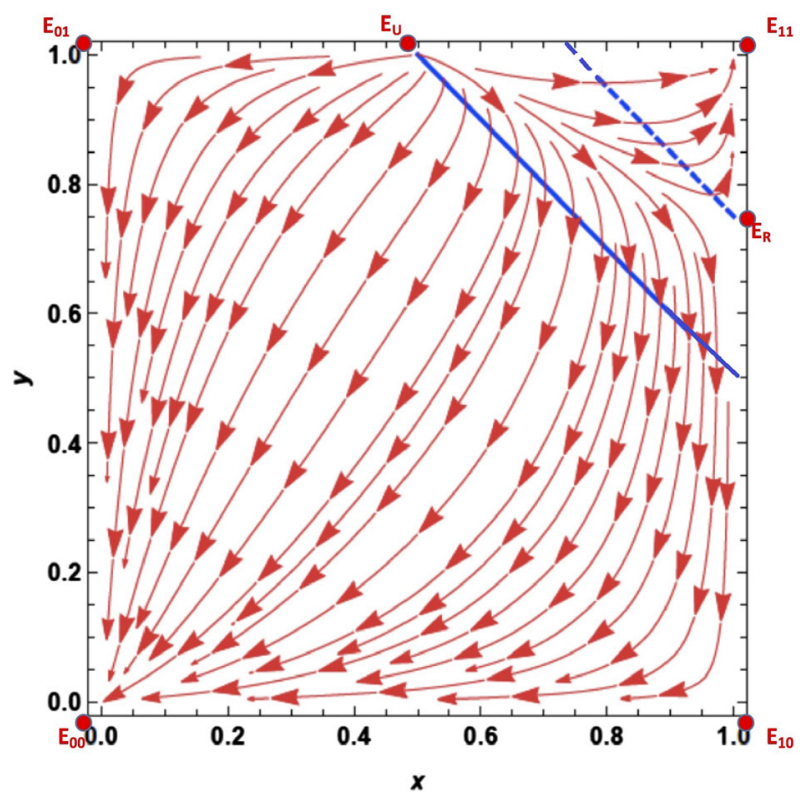

Fig. 4 Convergence toward supporting populism, $E_{00}$. . Source: Own elaboration using Wolfram Mathematica. Vector field of system (7). The parameters defined by $\sigma_{1}=0.4, \sigma_{2}=0.4, \beta_{1}=0.4$ and $\beta_{2}=0.4$ (for values lower than 0.4 we get the fully support of populism), and $\alpha=0.7, \gamma=0.7$ (it holds also for values higher than 0.7$)$. The straight blue line is $(1-x) x(-0.6+0.4 x+0.4 y)=0$, and the dashed blue line is $(1-y) y(-0.7+0.4 x+0.4 y)=0$, i.e., the two nullclines (color figure online)

Notice that in Fig. 3 the lower left corner shows that is possible to converge to full populist support (equilibrium $E_{00}$ ), despite the fact that the most cases are within the basin of attraction for not supporting populism. The boundary that separates the basins of attraction for $E_{00}$ and $E_{11}$ is given by the stable manifold of the saddle $E_{B}$. The aim is just to illustrate the path dependence of our results (Propositions 1 and 2), since the results of the system (7) depend on initial conditions, that is the profile distributions of citizens (Rich and Poor), we say that the model is historically dependent, because given the initial distributions of $x$ and $y$, the dynamic replicator system converges toward one of two distinct attractors, $E_{00}$ or $E_{11}$.

The next scenario considers a situation with high fear of immigrants and low inequality, represented by Fig. 4. Equilibrium $E_{00}$ represents full populists support by both groups in the long run. $E_{00}$ is stable under the condition: $\alpha>\bar{W}(\bar{\tau}-\tau)$, i.e., the constant fear of immigrants is large enough for the Rich group (Fig. 4).

Notice that in Fig. 4 the boundary that separates the basins of attraction of $E_{00}$ and $E_{11}$ is given by the stable manifold of the saddle $E_{R}$, so there are cases for which there is a convergence toward not supporting populism (the small basin of attraction in the upper right corner).

Hence, when inequality is not high $(\bar{W}=1)$ and given the redistribution policy regarding transfers and income taxation $(\bar{\tau}=0.4$ and $\tau=0.3)$, a society is supporting populism if the fear of immigrants in general is high, and if the marginal effects on the psychological benefit of not-supporting citizens is low, i.e., citizens are not much 


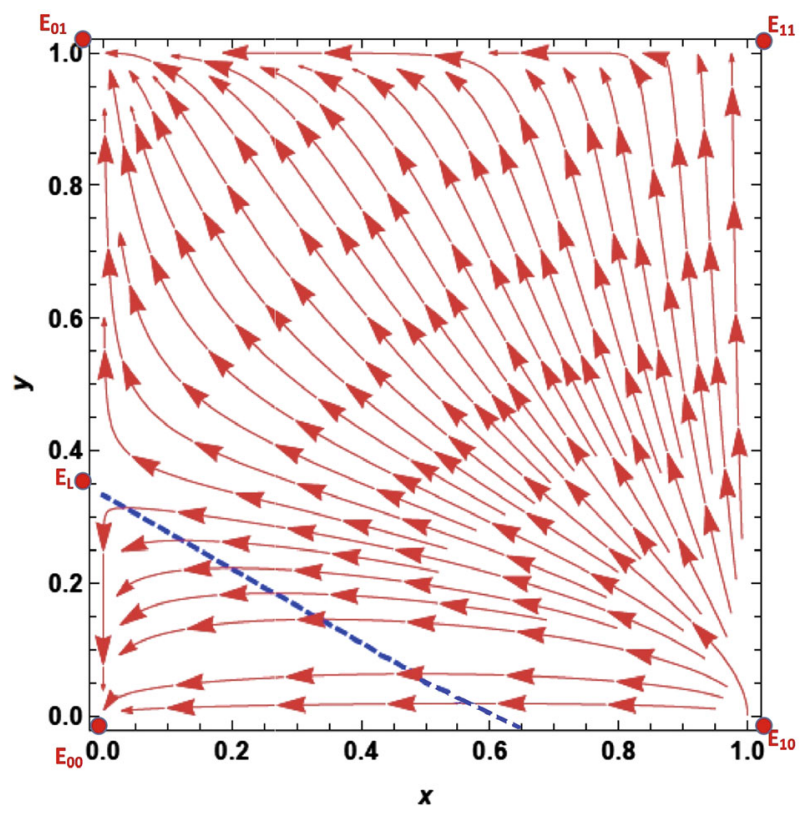

Fig. 5 Convergence toward a state of Rich supporting populism and some Poor non-supporting populism. . Source: Own elaboration using Wolfram Mathematica. Vector field of system (7). The parameters defined by $\sigma_{1}=0.9, \sigma_{2}=0.5, \beta_{1}=0.3$ and $\beta_{2}=0.5$, and $\alpha=0.9, \gamma=0.3$. The dashed blue line is $(1-y) y(-0.9+0.3 x+0.5 y)=0$, i.e., the nullcline (color figure online)

affected by those citizens who do not support populism. Therefore, in this second scenario both Rich and Poor citizens converge toward supporting populism unless the society starts from very low levels of populists' support.

\subsection{Populism by only one group}

A third scenario is depicted in Fig. 5. This scenario is the one with moderate levels of economic inequality, the Rich have a higher constant fear of immigrants and they lose little of their fear due to an increase of not supporting citizens. The equilibrium in which the Poor do not support Populism, but the Rich do is $E_{01}$. Intuitively, this equilibrium is reached when the elite considerably fears immigrants and it is willing to pay for it through the redistribution policy. This equilibrium is stable when: $\alpha>\beta_{2}+\bar{W}(\bar{\tau}-\tau)$ and $\gamma<\sigma_{1}$.

Note that given the parameters of Fig. 5, the boundary equilibrium $E_{L}$ exists being a saddle point with unstable manifold along the vertical edge since $\alpha>\frac{\gamma \beta_{2}}{\sigma_{1}}+\bar{W}(\bar{\tau}-\tau)$, and in this case there is a small basin of attraction (lower left) for both the rich and the poor supporting populism. That is, although we are in the case where the rich support populism, we are getting a small basin of attraction of $E_{00}$. Even if the Poor have a small constant fear of immigrants $(\gamma=0.3)$, they are heavily influenced by the Rich choice $(\sigma=0.9)$ so that their incentives for not supporting populists are outweighed. 


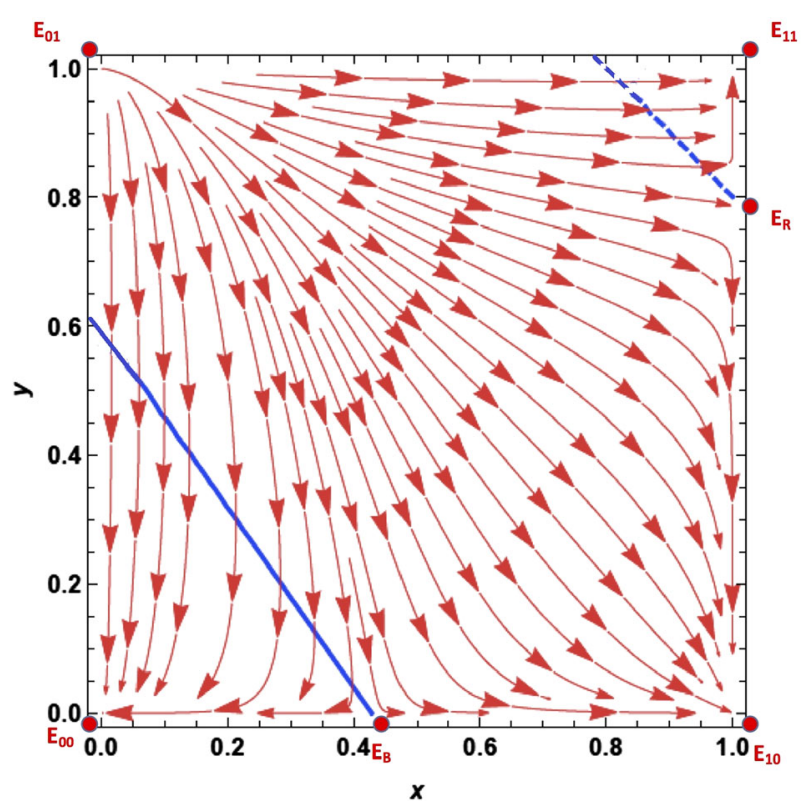

Fig. 6 Convergence toward a state of (divisions of social class) Rich non-supporting populism and Poor supporting populism. . Source: Own elaboration using Wolfram Mathematica. Vector field of system (7). The parameters defined by $\sigma_{1}=0.5, \sigma_{2}=0.5, \beta_{1}=0.7$ and $\beta_{2}=0.5$, and $\alpha=0.4, \gamma=0.7$. The straight blue line is $(1-x) x(-0.3+0.7 x+0.5 y)=0$, and the dashed blue line is $(1-y) y(-0.9+0.5 x+0.5 y)=0$, i.e., the two nullclines (color figure online)

Scenario four is depicted by Fig. 6 and consists in average levels of economic inequality and Poor that fear the immigrants, while the Rich do not. The equilibrium in which the Poor support populism but the Rich do not is $E_{10}$. This equilibrium point is an attracting node if the Rich do not fear immigrants, $\alpha<\beta_{1}+\bar{W}(\bar{\tau}-\tau)$, and the Poor do fear immigrants, $\gamma>\sigma_{2}$. Given the parameters of Fig. 6 the boundary equilibria $E_{B}$ and $E_{R}$ exist: the first means that a fraction of rich citizens support populism and all the Poor support it. The second means that all rich citizens do not support populism and a fraction of the poor goes toward the support of populism.

Intuitively, Fig. 6 shows what happens when the elite does not fear immigrants, but the Poor do. Notice that Fig. 6 represents a case where other equilibria exist such as the boundary equilibria $E_{B}$ and $E_{R}$. These two equilibria are unstable, while $E_{10}$, $E_{11}$ and $E_{00}$ are stable. The largest basin of attraction is the one of $E_{10}$, but it is still possible for certain starting points of shares of voters to converge in the long run to $E_{11}$ and $E_{00}$. For example, if a society starts from the Rich to fully support populists (despite the parametrization we assigned), then the long run equilibrium will be $E_{00}$ since the Poor in this scenario have a high fear of immigrants. Moreover, if society starts from a scenario of Poor not supporting populists above $80 \%$ of the population, then society will converge to $E_{11}$ since the fear of immigrants is eroded by a large initial majority that does not support the populists. 


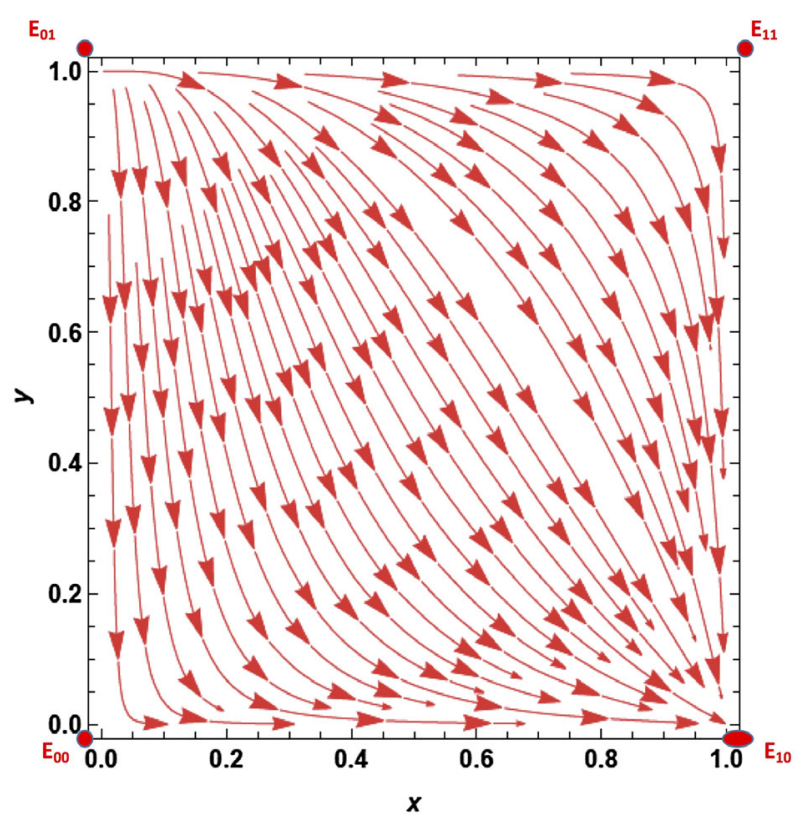

Fig. 7 Increasing wealth inequality: Rich non-supporting, Poor supporting, $E_{10}$.. Source: Own elaboration using Wolfram Mathematica. Vector field of system (7). The parameters defined by $\bar{W} \geq 8$ meaning high levels of wealth inequality, and $\alpha \geq 0.7, \gamma \geq 0.9$ meaning high fear of immigrants. While the transcritical bifurcation, $E_{10}=E_{B}$, is given by the parameters: $\bar{W}=5, \alpha=0.3$ and $\beta_{1}=0.8$

\subsection{Left-wing populism}

In the previous simulation results we assumed a low economic inequality $\bar{W}=1$, and considered a tax and transfer policy given by $\bar{\tau}=0.4, \tau=0.3$. However, left-wing populism is characterized by a high level of income and wealth inequality that we simulate in the scenario represented in Fig. 7. There is one asymptotically stable equilibrium, $E_{10}$, which is stable when the wealth of the Rich is high enough, $\bar{W} \geq \frac{\alpha-\beta_{1}}{(\bar{\tau}-\tau)}$; equality indicates that a trasncritical bifurcation occurs, i.e., $E_{10}=E_{B}$.

Several conditions are present at the same time:

1. Very high wealth inequality, $\bar{W}$ that fuels support for populists from the Poor and lack of support from the Rich.

2. Low to middle level of $\alpha$ and $\beta_{1}, \beta_{2}$, that is there is a middle to big positive marginal effect for fellow citizens supporting populism. This means trust that support for populist parties will imply better efficacy of populist policies on immigration.

3. Low or middle level of $\gamma$, i.e., both the rich and the poor care little on average about immigrants. 

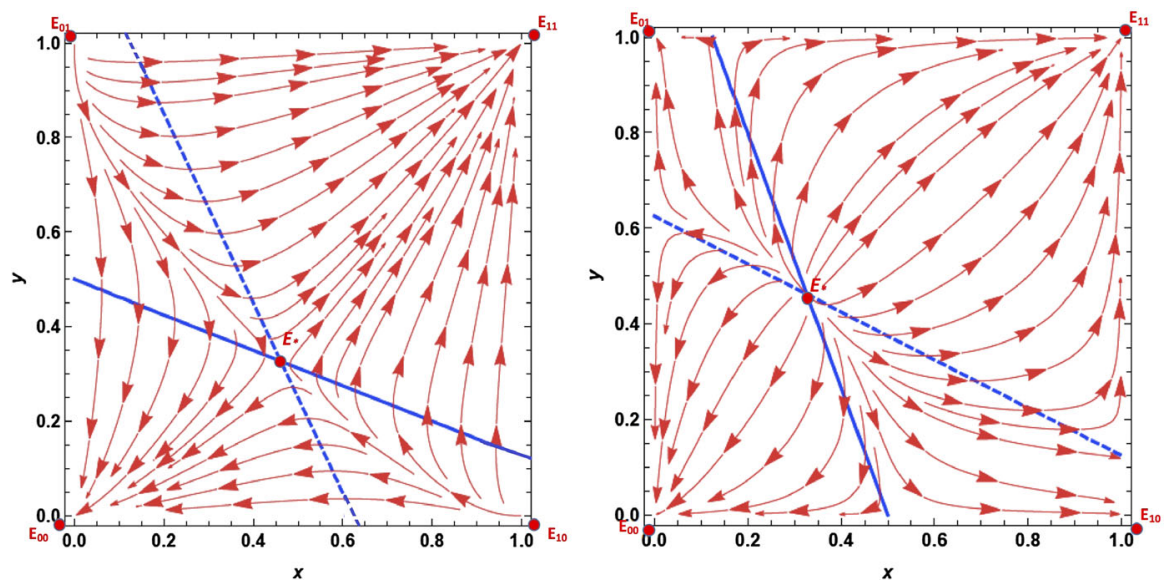

Fig. 8 European populism cannot be defeated-but it can be contained. . Source: Own elaboration using Wolfram Mathematica. Vector field of system (7). The parameters defined by $\bar{W}=1, \alpha=0.5$ and $\gamma=0.5$ meaning that there is not wealth inequality and half of citizens fear immigrants but the other half do not fear it. On the figure left, the straight blue line is $(1-x) x(-0.4+0.3 x+0.8 y)=0$, and the dashed blue line is $(1-y) y(-0.5+0.8 x+0.4 y)=0$, i.e., the two nullclines. On the figure right, the straight blue line is $(1-x) x(-0.4+0.8 x+0.3 y)=0$, and the dashed blue line is $(1-y) y(-0.5+0.4 x+0.8 y)=0$, i.e., the two nullclines (color figure online)

\subsection{European right-wing populism}

Let us consider now a scenario where there is low wealth inequality and middle level of fear of immigrants. It is interesting to study the interior equilibrium $\left(x^{*}, y^{*}\right)$ that can be either a saddle point (i.e., with the exception of a single curve (line) through this point, all solution trajectories converge to $(1,1)$ or $(0,0))$ or a repulsor, see Fig. 8.

To illustrate this case, let us consider that there is low wealth inequality ( $\bar{W}=1$ ), and the fear of immigrants has an average value, $(\alpha=0.5, \gamma=0.5)$. This interior equilibrium is a repulsor (right side Fig. 8) if $\sigma_{1}>\sigma_{2}$ and $\beta_{1}>\beta_{2}$, meaning that each group cares more about its own type (the rich are affected more by how their group is composed, the poor by how their group is composed). On the other hand, this interior equilibrium is a saddle (left side Fig. 8) if $\sigma_{2}>\sigma_{1}$ and $\beta_{2}>\beta_{1}$, meaning that each group cares more about how the other group is composed.

Some remarks for this scenario:

- Wealth and income inequality need to be low: lower than 5.1 for the parameters' representation of Fig. 8. (if not, there is no longer an interior equilibrium and the case becomes the left-wing populism/South American)

- In this setup, in the figure to the right every group cares marginally more about their fellow group members. That is, the Poor care marginally more if a Poor citizen becomes a supporter of populists than if a Rich one moves.

- In the figure to the left, every group cares marginally more about the other group members. 
- For both figures, an increase in $\alpha$ and/or $\gamma$ (a constant fear of immigrants by the rich and the poor, respectively) shifts the interior equilibrium such that the basin of attraction toward the equilibrium $(S, S)$ is larger.

This setup gives us an answer to the initial questions: Why is populism emerging now in Europe? How do stable democracies with mild levels of economic and social problems suddenly see an important spike of preferences for populist parties? This framework answers that an increase in the salience of immigration and an increase in economic inequality (while still being at mild levels of it) causes the interior equilibrium to change such that the basin of attraction of the full support to populists is larger. This means that the long-term causes for populists' surge will be difficult to reverse if economic inequality and salience of immigration continue to go upward.

\subsection{Avoiding populism}

According to our dynamic model, escaping from populism is possible if: (1) a specific transcritical bifurcation occurs (starting from the European right-wing case) or (2) the basin of attraction toward the $E_{00}$ equilibrium shrinks up to vanishing. Let's give an explanation of how to achieve these outcomes.

There may be a transcritical bifurcation (or stability exchange) given the fixed parameters from Fig. 8, but increasing wealth inequality to $\bar{W}=5$ : then the interior equilibrium (the repulsor in Fig. 8) ends up on a boundary equilibrium $E_{L}$ which is a repelling node (see Fig. 9), i.e., $E_{*}=E_{L}=\left(0, \frac{\gamma}{\sigma_{1}}\right)$, since $\bar{W}(\bar{\tau}-\tau)>\alpha-\frac{\beta_{1} \gamma}{\sigma_{1}}$.

Figure 9 shows that an increase in wealth implies that rich citizens converge toward non-supporting populism, and therefore fear of immigrants becomes a secondary issue. Such an increase of $\bar{W}(\bar{\tau}-\tau)$ means greater wealth for rich citizens but also greater transfers to the poor, since the proportion of this wealth that is paid in taxes goes directly to the increase in transfers.

Let us emphasize that we are not claiming that an economic inequality must be generated, instead we claim that what is needed is an egalitarian economic society with a high degree of altruism and cooperation toward the immigrants. Numerically, if $\bar{W}=1$, and the fear of immigrants is low, $\alpha=0.1, \gamma=0$, the strategy of supporting populism is no longer a stable strategy but rather it is unstable, and citizens converge to the non-populist equilibrium $E_{11}$, see Fig. 10.

\subsection{Replicator dynamic with idiosyncratic behavior}

The evolutionary (replicator) dynamic (7) is based exclusively on observing the payoff associated with both strategies. This dynamic therefore ignores agent specific idiosyncrasies and may eliminate plausible long-run equilibria with heterogeneous citizens behavior. In this section, we present the replicator dynamics given by a sort of idiosincratically behavior, i.e., a convex combination of strategies, where a share of citizens randomly chooses a strategy without taking into account strategy payoffs. That is, by adding a certain number of agents that choose "random" whether to support or not populism, i.e., the probabilities are the degree of supporting or not populism varieties. 


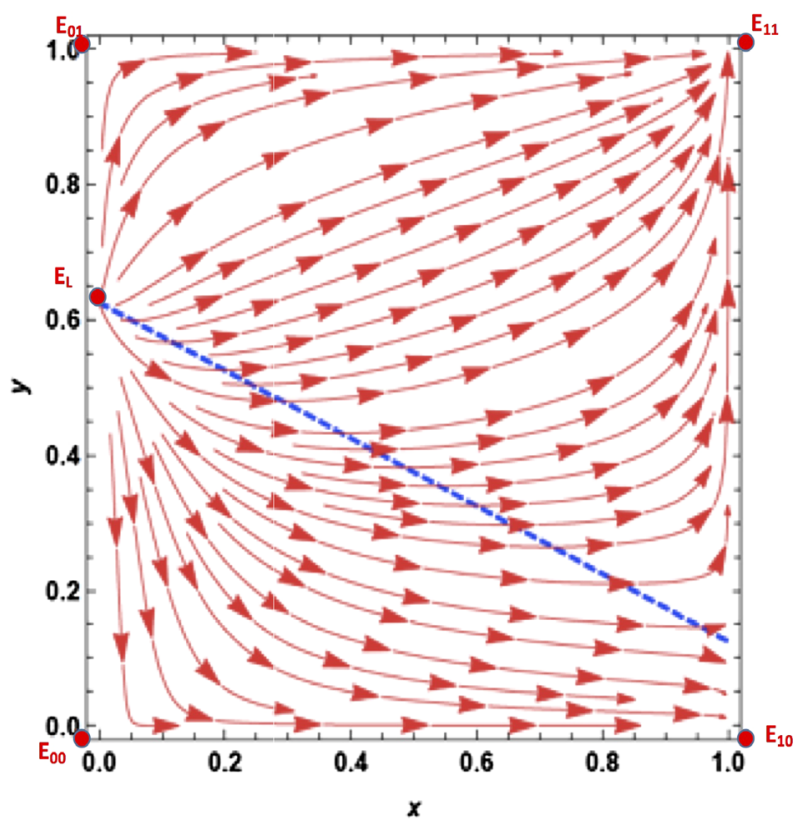

Fig. 9 Increasing wealth, and fear of immigrants as a secondary issue.. Source: Own elaboration using Wolfram Mathematica. Vector field of system (7). The parameters defined by $\bar{W}=5.1, \alpha=0.5, \gamma=$ $0.5, \sigma_{1}=0.4, \sigma_{2}=0.8$, and $\beta_{1}=0.3, \beta_{2}=0.8$. The dashed blue line is $(1-y) y(-0.5+0.4 x+0.8 y)=$ 0 (color figure online)

Idiosyncratic change is given by rational choice-based analysis of models of electoral system change (Arter 2019), because of a variety of explanations (institutional, non-institutional, sociological etc.) used to account for voting change driven by an idyosincratic behavior.

Formally, let $\theta \in(0,1)$ be the share of rich citizens that choose one of the strategies at random with equal probability. Assume that they do so, whenever they observe an $N S$-rich citizen interacting with an $S$-citizen, which happens with probability $x(1-x)$. The share of $N S$-rich citizens is defined by $\theta x$ and the share of $S$-rich citizens by $\theta(1-x)$, with half of each share changing strategy. The net increase in $N S$-rich through random choice is thus:

$$
x(1-x) \theta(1-x) \frac{1}{2}-(1-x) x \theta x \frac{1}{2}=\theta x(1-x)\left(\frac{1}{2}-x\right) .
$$

Analogously for the poor population, let $\rho \in(0,1)$ be the share of poor citizens that choose one of the strategies at random with equal probability. The net increase in $N S$-poor through random choice is thus:

$$
y(1-y) \rho(1-y) \frac{1}{2}-(1-y) y \rho y \frac{1}{2}=\rho y(1-y)\left(\frac{1}{2}-y\right) .
$$




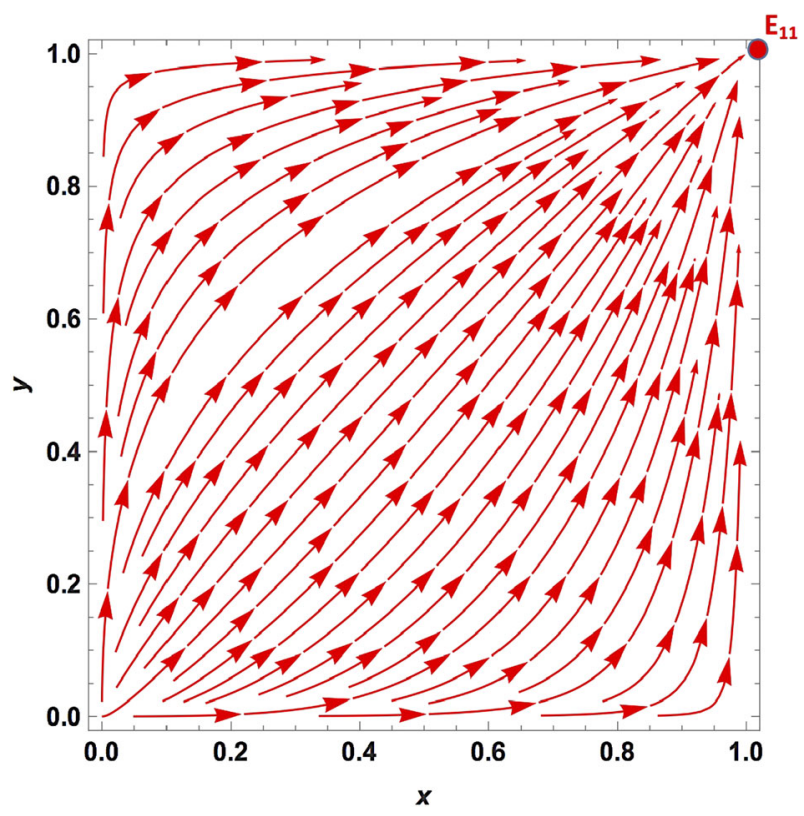

Fig. 10 Egalitarian economic society vanishes populism. . Source: Own elaboration using Wolfram Mathematica. Vector field of system (7). The parameters defined by $\bar{W}=1, \alpha=0.1, \gamma=0, \sigma_{1}=0.4, \sigma_{2}=$ 0.8 , and $\beta_{1}=0.3, \beta_{2}=0.8$

Redefining the replicator dynamic in (7) for the rich and poor population, we obtain:

$$
\left\{\begin{array}{l}
\dot{x}=x\left[E_{N S}^{R}(\cdot)-\bar{E}^{R}\right] \\
=x(1-x)\left[(1-\theta)\left(\bar{W}(\bar{\tau}-\tau)-\alpha+\beta_{1} x+\beta_{2} y\right)+\theta\left(\frac{1}{2}-x\right)\right] \\
\dot{y}=y\left[E_{N S}^{P}(\cdot)-\bar{E}^{P}\right]=y(1-y)\left[(1-\rho)\left(\sigma_{1} y+\sigma_{2} x-\gamma\right)+\rho\left(\frac{1}{2}-x\right)\right]
\end{array}\right.
$$

This dynamic (10) is also characterized by nine stationary states (four corners, four boundaries, and an interior one), however the interesting case now is the interior equilibrium which turns out to be locally stable.

That is, citizens randomly choosing whether or not to support populism result in a society or economy where there are fractions of populist people opposed to other fractions of non-populist people, and this situation is locally stable (see Fig. 11).

\section{Conclusion}

This paper gives a possible answer to the questions raised all over Europe: why is populism emerging? How do stable democracies with mild levels of economic and social problems suddenly see an important spike of preferences for populist parties? 


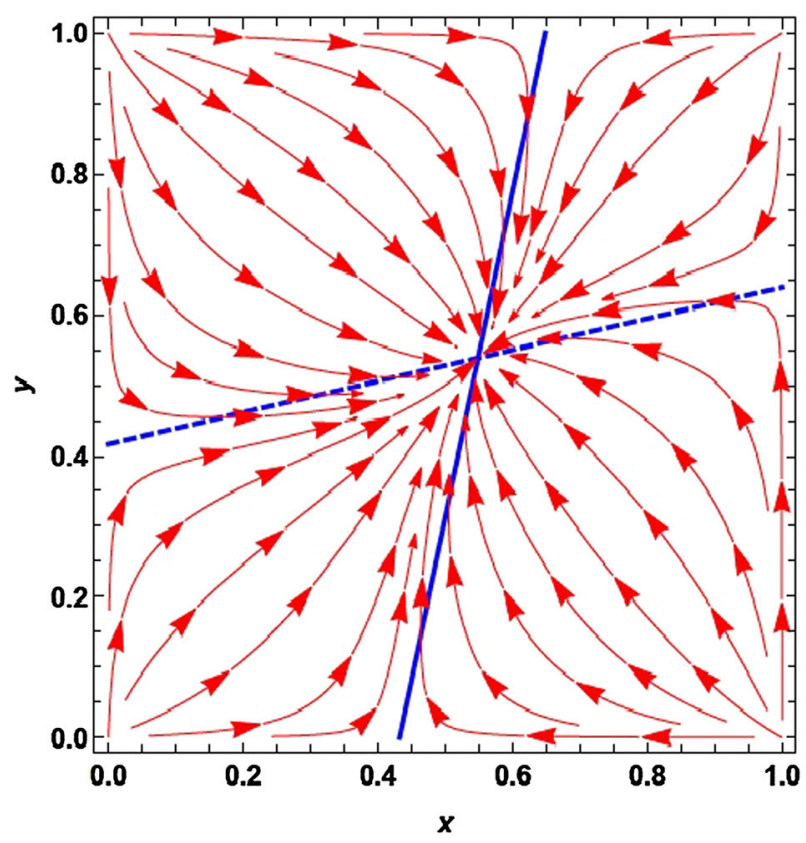

Fig. 11 Idiosyncratic voting. . Source: Own elaboration using Wolfram Mathematica. Vector field of system (10). The parameters defined by $\bar{W}=1, \rho=0.8, \theta=0.8, \alpha=0.5, \gamma=0.5, \beta_{1}=0.3, \beta_{2}=0.8$, and $\sigma_{1}=0.4, \sigma_{2}=0.8$

We have built a political economy evolutionary game that gives us an answer: an increase in the salience of immigration and an increase in economic inequality (starting from a mild level of it), fuel a change in the interior equilibrium of our game, such that the basin of attraction of the full populist support becomes larger. This means that these two long-term shocks changed the incentive to support the populists. Our model predicts that unless these two political demands change, the populist support is likely to be sustained. Our model cannot distinguish between different populist parties with a specific political strength (for example in Italy, the League with regards to immigration and the 5 Star Movement with regards to redistribution), but it provides one framework to interpret the populist support in relation to two well-documented data.

In addition, our model explains the dynamics of left-wing populism, typically from the South-American countries: if the immigration threat is absent or negligible, populism becomes strictly a matter of redistribution. The higher the income inequality, the higher the political clash between an elite that wants to preserve its wealth and a vast majority of the population that craves for redistribution. Future research on populism may quantify to what extent psychological effects influence votes and how extensive group decisions on voting are as opposed to individual ones. Moreover, we may consider if is it time to change economic policies. What can be done to stop the surge of populism? 
Insofar as populist support is fueled by economic inequality and a fear of immigration, governments can respond with policies to improve matters. For example, by providing more redistributive taxes and more education.

This is a condition for not supporting populism: an economy characterized by greater wealth and higher labor income but also higher taxes allocated to social programs for the poor. Moreover, another way to escape from populism is eliminating its basin of attraction, and this happens when the poor do not perceive any fear of immigrants, and when the fear of immigrants by the rich equals the dislike for redistribution, making that fear a second-order issue.

Acknowledgements We thank the Editors and the anonymous reviewers for their constructive comments, which helped us to improve the manuscript. We benefitted from discussions and comments from Angelo Antoci, Costas Azariadis, Marwil Davila-Fernandez, Roberto Dieci, Laura Gardini, Mario R. Gilli, Germana Giombini, Luca Gori, Sebastian Ille, Thomas Konig, Elena Manzoni, James Newell, Laura Policardo, Dani Rodrik, Barkley Rosser, Mauro Sodini, Davide Ticchi, Giuseppe Travaglini. We thank seminar participants at PhD in Global Studies at DESP-University of Urbino, the CefES2019 (Center for European Studies) Conference at The University of Milan-Bicocca, and The conference on Nonlinear Economic Dynamics (NED) at Kyiv School of Economics. This research work has been developed in the framework of the research project on "Models of behavioral economics for sustainable development" financed by DESP-University of Urbino. The usual disclaimer applies.

Funding Open access funding provided by Università degli Studi di Urbino Carlo Bo within the CRUICARE Agreement.

\section{Compliance with ethical standards}

Conflict of interest The authors declare that there is no conflict of interest.

Open Access This article is licensed under a Creative Commons Attribution 4.0 International License, which permits use, sharing, adaptation, distribution and reproduction in any medium or format, as long as you give appropriate credit to the original author(s) and the source, provide a link to the Creative Commons licence, and indicate if changes were made. The images or other third party material in this article are included in the article's Creative Commons licence, unless indicated otherwise in a credit line to the material. If material is not included in the article's Creative Commons licence and your intended use is not permitted by statutory regulation or exceeds the permitted use, you will need to obtain permission directly from the copyright holder. To view a copy of this licence, visit http://creativecommons.org/licenses/by/4.0/.

\section{Appendix}

Proof of the Proposition on existence and stability of equilibrium points

The equilibrium points are the solutions of the ninth degree algebraic system of two equations

$$
\left\{\begin{array}{l}
x(1-x)\left[\bar{W}(\bar{\tau}-\tau)-\alpha+\beta_{1} x+\beta_{2} y\right]=0 \\
y(1-y)\left[\sigma_{1} y+\sigma_{2} x-\gamma\right]=0
\end{array}\right.
$$

In particular, a unique interior equilibrium $E_{*}=\left(x^{*}, y^{*}\right)$, located at the unique intersection of the two lines (nullclines) 


$$
\begin{aligned}
& \beta_{1} x+\beta_{2} y=\alpha-\bar{W}(\bar{\tau}-\tau) \\
& \sigma_{2} x+\sigma_{1} y=\gamma
\end{aligned}
$$

exists provided that $\sigma_{1} \beta_{1} \neq \sigma_{2} \beta_{2}$, and it is feasible if $0 \leq x^{*} \leq 1$ and $0 \leq y^{*} \leq 1$.

The local stability of the each equilibrium point is determined through the usual linearization procedure, i.e., according to the study of the eigenvalues of the Jacobian matrix

$$
(x, y)=\left[\begin{array}{cc}
(1-2 x)\left(\bar{W}(\bar{\tau}-\tau)-\alpha+\beta_{1} x+\beta_{2} y\right)+(1-x) \beta_{1} x & \beta_{2} x(1-x) \\
\sigma_{2} y(1-y) & \sigma_{1} y(1-y)+(1-2 y)\left(\sigma_{2} x+\sigma_{1} y-\gamma\right)
\end{array}\right]
$$

computed at the equilibrium points. At the interior equilibrium $E_{*}$ we have

$$
J\left(x^{*}, y^{*}\right)=\left[\begin{array}{ll}
\beta_{1} x^{*}\left(1-x^{*}\right) & \beta_{2} x^{*}\left(1-x^{*}\right) \\
\sigma_{2} y^{*}\left(1-y^{*}\right) & \sigma_{1} y^{*}\left(1-y^{*}\right)
\end{array}\right]
$$

The sufficient conditions for the stability, i.e., the conditions for both the eigenvalues have negative real part, are given by the Routh-Hirwitz Criterion (see, e.g., Gandolfo 2010; Medio and Lines 2001) $\operatorname{Tr}(J)=\beta_{1} x^{*}\left(1-x^{*}\right)+\sigma_{1} y^{*}\left(1-y^{*}\right)<0$ and $\operatorname{Det}(J)=x^{*} y^{*}\left(1-x^{*}\right)\left(1-y^{*}\right)\left(\beta_{1} \sigma_{1}-\beta_{2} \sigma_{2}\right)>0$, where $\operatorname{Tr}(J)$ and $\operatorname{Det}(J)$ represent the trace and the determinant of the Jacobian matrix, respectively.

The first condition is never satisfied when the equilibrium $E_{*}$ exists inside the unit square, hence such equilibrium is always unstable. In particular, as the eigenvalues are always real being $\operatorname{Tr}(J)^{2}-4 \operatorname{Det}(J)=\left[\beta_{1} x^{*}\left(1-x^{*}\right)-\sigma_{1} y^{*}\left(1-y^{*}\right)\right]^{2}+$ $4 \beta_{2} \sigma_{2} x^{*} y^{*}\left(1-x^{*}\right)\left(1-y^{*}\right)>0$, the equilibrium $E_{*}$ is a saddle point if $\operatorname{Det}(J)<0$, i.e., $\beta_{1} \sigma_{1}<\beta_{2} \sigma_{2}$ whereas it is an unstable node if $\operatorname{Det}(J)>0$, i.e., $\beta_{1} \sigma_{1}>\beta_{2} \sigma_{2}$, see, e.g., ...

The stability analysis at the corner equilibria, as well as at the boundary equilibria, is straightforward, as the Jacobian matrix is diagonal at any corner equilibrium and triangular at any boundary equilibrium, hence in both cases the eigenvalues are given by the diagonal entries. For example, at $E_{00}$ we have

$$
J(0,0)=\left[\begin{array}{cc}
\bar{W}(\bar{\tau}-\tau)-\alpha & 0 \\
0 & -\gamma
\end{array}\right]
$$

hence, being the eigenvalue $-\gamma$ always negative, the only condition for stability of $E_{00}$ is $\bar{W}(\bar{\tau}-\tau)-\alpha<0$. This implies that $E_{00}$ is a stable node, whereas it is a saddle if the inequality is reversed, with unstable manifold along the vertical axis. Analogously, from

$$
J(1,1)=\left[\begin{array}{cc}
\alpha-\beta_{1}-\beta_{2}-\bar{W}(\bar{\tau}-\tau) & 0 \\
0 & \gamma-\sigma_{1}-\sigma_{2}
\end{array}\right]
$$

from the conditions of negativity of the two diagonal entries we get the conditions for $E_{11}$ being a stable node, whereas if both the inequalities are reversed it is an unstable node and if only one is reversed, i.e., the eigenvalues are one negative and 
one positive, then $E_{11}$ is a saddle point with stable and unstable manifolds along the horizontal and vertical directions. Analogous arguments can be applied to the other two corner equilibria. Instead, the Jacobian matrix computed at the boundary equilibria assumes the structure of a triangular matrix. In this case, the eigenvalues are, again, the diagonal entries but one invariant set is no longer parallel to a coordinate axis, as it is transverse to it. For example, at the left boundary equilibrium $E_{L}$ we get

$$
J\left(0, \frac{\gamma}{\sigma_{1}}\right)=\left[\begin{array}{cc}
\bar{W}(\bar{\tau}-\tau)-\alpha+\frac{\beta_{2} \gamma}{\sigma_{1}} & 0 \\
\sigma_{2} \frac{\gamma}{\sigma_{1}}\left(1-\frac{\gamma}{\sigma_{1}}\right) & \gamma\left(1-\frac{\gamma}{\sigma_{1}}\right)
\end{array}\right]
$$

hence, being $\left(1-\frac{\gamma}{\sigma_{1}}\right)>0$ whenever $E_{L}$ is feasible, i.e., interior to the unit interval, $E_{L}$ is a saddle point if $\alpha>\bar{W}(\bar{\tau}-\tau)+\frac{\beta_{2} \gamma}{\sigma_{1}}$, with unstable manifold along the vertical invariant edge and unstable one transverse to it (but not orthogonal), whereas $E_{L}$ is an unstable node if if $\alpha<\bar{W}(\bar{\tau}-\tau)+\frac{\beta_{2} \gamma}{\sigma_{1}}$. An analogous analysis proves the stability properties for the other boundary equilibria.

\section{References}

Acemoglu D, Erogov G, Sonin K (2013) A political theory of populism. Quart J Econ 128(2):771-805

Aggeborn L, Persson L (2017) Public finance and right-wing populism. In: Research Institute of Industrial Economics, IFN working paper series, n.1182

Aichholzer J, Zandonella M (2016) Psychological bases of support for radical right parties. Pers Individ Differ 96:185-190

Algan Y, Beasley E, Cohen D, Foucault M (2018) The rise of populism and the collapse of the left-right paradigm: lessons from the 2017 French presidential election. In: CEPR discussion paper 13103

Algan Y, Guriev S, Papaioannou E, Passari E (2017) The European trust crisis and the rise of populism. In: CEPR discussion paper, n. 12444

Antoci A, Sabatini F (2018) Online networks, social interaction and segregation: an evolutionary approach. J Evol Econ 28(4):859-883

Antoci A, Fiori Maccioni A, Luigi Sacco P, Sodini M (2017) Self-protection, psychological externalities, and the social dynamics of fear. J Confl Resolut Peace Sci Soc (Int) 61(2):349-371

Arter D (2019) Idiosyncratic, technocratic, democratic or simply pragmatic? A parties' perspective on electoral system change in Finland, 1906-1969. Politiikka 61(1):34-53

Autor D, Dorn D, Hanson GH (2016) The China shock: learning from labor-market adjustment to large changes in trade. Annu Rev Econ 8:205-240

Autor D, Dorn D, Hanson G, Majlesi K (2016) Importing political polarization?. Massachusetts Institute of Technology Manuscript

Berelson BR, Lazarsfeld PF, McPhee WN, McPhee WN (1954) Voting: a study of opinion formation in a presidential campaign. University of Chicago Press, Chicago

Bischi G, Merlone U, Pruscini E (2018) Evolutionary dynamics in club goods binary games. J Econ Dyn Control 91:104-119

Blanchet T, Chancel L, Gethin A (2019) How unequal is Europe? evidence from distributional national accounts. In: WID.world working paper 2019/6

Card D, Dustmann C, Preston I (2012) Immigration, wages, and compositional amenities. J Eur Econ Assoc 10(1):78-119

Colantone I, Stanig P (2018) The trade origins of economic nationalism: import competition and voting behavior in Western Europe. Am J Polit Sci 62(4):936-953

De Bromhead A, Eichengreen B, O’Rourke KH (2013) Political extremism in the 1920s and 1930s: do German lessons generalize? J Econ Hist 73(2):371-406 
Dennison J, Geddes A (2018) A rising tide? the Salience of immigration and the rise of anti-immigration political parties in Western Europe. Polit Quart 90(1):107-116

Dorn F, Fuest C, Immel L, Neumeier F (2018). Inequality and extremist voting: evidence from Germany

Di Tella R, Rotemberg JJ (2018) Populism and the return of the 'Paranoid Style': some evidence and a simple model of demand for incompetence as insurance against elite betrayal. J Comp Econ 46(4):988-1005

Dornbusch R, Edwards S (1991) The macroeconomics of populism in Latin America. University of Chicago Press, Chicago

Dustmann C, Eichengreen B, Otten S, Sapir A, Tabellini G, Zoega G (2017) Europe's trust deficit

Dustmann C, Preston IP (2007) Racial and economic factors in attitudes to immigration. BE J Econ Anal Policy 7(1)

EEAG, The EEAG Report on the European Economy (2017) Economic policy and the rise of populism-it's not so simple. CESifo, Munich, pp 50-66. https://www.ifo.de/DocDL/eeag-2017-economic-policyand-the-rise-of-populism.pdf

Favaretto F, Masciandaro D (2020) Populism, group thinking and banking policy. In: BAFFI CAREFIN centre research paper (2020-133)

Funke M, Schularick M, Trebesch C (2016) Going to extremes: politics after financial crises, 1870-2014. Eur Econ Rev 88:227-260

Gandolfo G (2010) Economic dynamics, 4th edn. Springer, Berlin

Georgiadou V, Rori L, Roumanias C (2018) Mapping the European far right in the 21st century: a meso-level analysis. Electoral Stud 54:103-115

Gerber AS, Rogers T (2009) Descriptive social norms and motivation to vote: everybody's voting and so should you. J Polit 71(1):178-191

Gintis H (2009) Game theory evolving, 2nd edn. Princeton University Press, Princeton

Golder M (2016) Far right parties in Europe. Annu Rev Polit Sci 19:477-497

Guiso L, Herrera H, Morelli M, Sonno T (2017) Demand and supply of populism. Mimeo, New York

Han KJ (2016) Income inequality and voting for radical right-wing parties. Electoral Stud 42:54-64

Huckfeldt RR, Sprague J (1995) Citizens, politics and social communication: information and influence in an election campaign. Cambridge University Press, Cambridge

Inglehart RF, Norris P (2016) Trump, brexit and the rise of populism: economic have-nots and cultural backlash. In: Harvard Kennedy School, Research working paper series, n. 26

Maynard Smith J (1972) On Evolution. Edinburgh University Press, Edinburgh

Maynard Smith J, Price GR (1973) The logic of animal conflict. Nature 246(1973):15-18

Medio A, Lines M (2001) Nonlinear dynamics. Cambridge University Press, Cambridge

Moriconi S, Peri G, Turati R (2018) Skill of the immigrants and vote of the natives: immigration and nationalism in European elections 2007-2016 (No. w25077). National Bureau of Economic Research

Mutz DC, Mondak JJ (1997) Dimensions of sociotropic behavior: group-based judgements of fairness and well-being. Am J Polit Sci 284-308

Passarelli F, Tabellini G (2017) Emotions and political unrest. J Polit Econ 125(3):903-946

Pastor L, Veronesi P (2018). Inequality aversion, populism, and the backlash against globalization (No. w24900). National Bureau of Economic Research

Rodrik D (2018) Populism and the economics of globalization. J Int Bus Policy 1:12-33

Sanchez Carrera E (2019) Evolutionary dynamics of poverty traps. J Evol Econ 29(2):611-630

Sanchez Carrera E (2016) Evolutionary games and poverty traps. Cambridge Scholars Publishing, Cambridge

Selten R (1975) Reexamination of the perfectness concept for equilibrium points in extensive games. Int J Game Theory 4:25-55

Schelling TC (1969) Models of segregation. Am Econ Rev 59(2):488-93

Schelling TC (1971) Dynamic models of segregation. J Math Soc 1(1):143-86

Tajfel H (1982) Social psychology of intergroup relations. Annu Rev Psychol 33(1):1-39

Taylor P (1979) Evolutionarily stable strategies with two types of player. J Appl Prob 16:76-83

Taylor PD, Jonker LB (1978) Evolutionary stable strategies and game dynamics. Math Biosci 40:145-156

Weibull WJ (1995) Evolutionary game theory. MIT Press, Cambridge, MA

Publisher's Note Springer Nature remains neutral with regard to jurisdictional claims in published maps and institutional affiliations. 